\title{
A FILOSOFIA E A MÚSICA NA FORMAÇÃO DE ADORNO
}

\author{
BRUNO PUCCI
}

RESUMO: Este ensaio se propõe a rastrear, no transcurso de sua vida e de seus escritos, a seguinte asserção de Adorno: "Estudei filosofia e música. Em vez de me decidir por uma, sempre tive a impressão de que perseguia a mesma coisa em ambas", e mostrar como a relação contínua e dialética entre música e filosofia foi fecunda em sua formação educacional e científica, bem como na constituição de seu original pensamento filosófico.

Palavras-chave: Teoria crítica e educação. Dialética negativa. Música e filosofia. Teoria estética.

\section{Philosophy and music in the "Bildung" of Adorno}

ABSTRACT: This paper goes into the biography and writings of Theodor Adorno to detect the relevance of his statement: "I studied philosophy and music. Instead of deciding for one or the other, I always had the impression that I pursued the same thing in both". It thereby attempts to show how the ongoing dialectical relationship between music and philosophy was fruitful for both his scientific and educational upbringing, and the constitution of his original philosophical thought.

Key words: Critical theory and education. Negative dialectics. Music and philosophy. Aesthetic theory.

Professor Titular do PPGE da UNIMEP, pesquisador do CNPQ e da FAPESP e coordenador do Grupo de Estudos e Pesquisa "Teoria Crítica e Educação”. E-mail: bpucci@unimep.br 

de vida. Theodor Wiesengrund Adorno nasceu em 11 de setembro de 1903 em Frankfurt am M ain. Seu pai, O skar W iesengrund, um próspero comerciante atacadista de vinhos, e sua mãe, Maria Calvelli Adorno, de origem corso-genovesa, cantora profissional de renome, antes do casamento. Agathe, tia solteira, irmã de sua mãe e companheira de lar, uma pianista talentosa. Ao som das sinfonias de M ozart e Beethoven tocadas ao piano pela tia e dos Lieder populares ou trechos de ópera interpretados por sua mãe, desenvolveu uma infância feliz e uma adolescência segura.

A filosofia não demora a aparecer em seus dias. Aos 15 anos de idade, em companhia de um amigo da família, 14 anos mais velho que ele - Siegfried Kracauer - , envolve-se com a leitura semanal da "C rítica da razão pura", de Kant. Longas conversações filosóficas são tecidas durante anos, aos sábados. C om 16 anos estuda composição com Bernhard Sekles no conservatório de H och. Aos 18 anos ingressa na recém-fundada U niversidade Johann Wolfgang Goethe, para ouvir/ estudar ainda mais filosofia e, nesse mesmo ano, sob a orientação de Kracauer, lê 0 espírito da utopia, de Ernst Bloch - filosofia - e A teoria do romance, de G eorge Lukács - filosofia e arte.

C resceu em um ambiente dominado por interesses artísticos e teóricos e foi encorajado pelos pais e amigos a desenvolver seus dotes em ambas as direções. Ele mesmo nos dá conta disso: "Estudei filosofia e música. Em vez de me decidir por uma, sempre tive a impressão de que perseguia a mesma coisa em ambas" (Adorno, 2002, p. 9).

Em 1922, com 19 anos, conhece Horkheimer - filósofo - em um seminário sobre $\mathrm{H}$ usserl e, no ano seguinte, Benjamin - esteta e filósofo. Com ambos estabelecerá relações de intensa amizade e de fecundas produções científicas, mas seu amigo e mentor da época era mesmo Kracauer. Em 1924, com 21 anos, defende sua tese de doutorado: A transcendência do objeto e do noemático na fenomenologia de H usserl, sob orientação de $\mathrm{H}$ ans Cornelius - filósofo de tendências progressistas, e, ao mesmo tempo, pianista, escultor, pintor e autor de estudos de estética e de pedagogia da arte.

Em 1925 vai para Viena estudar música com profissionais do círculo vanguardista de Schoenberg. Seus estudos, com Eduard Steuermann e Alban Berg, voltaram-se para piano e composição. Além dos mestres citados, os músicos Rudolf Kolisch e Anton 
Webern também faziam parte de seu grupo de conversações. Entre 1928 e 1929 foi editor da revista Anbruch, de Viena, em prol da música mais moderna radical.

Visivelmente mais talentoso como comentarista de música que como compositor, não se sentindo reconhecido no círculo de Schoenberg e com saudade de sua cidade natal, regressou a Frankfurt no verão de 1925. N ão tinha abandonado, porém, seu projeto de tornar-se músico, mas cultivou cada vez mais a esperança de fazer uma carreira universitária em filosofia, centrada na estética. A influência da temporada na capital austríaca foi decisiva em sua formação musical e filosófica; o rigor da composição e da expressão de seus ensaios, sua filosofia atonal devem-se muito a esse período.

De 1922 a 1933, Adorno acompanhou como crítico a Konzertleben (vida musical) de Frankfurt. Escreveu uma centena de pequenos artigos, hoje reunidos sob o título "Críticas das óperas e concertos de Frankfurt". A vida musical era um dos principais temas do debate público de sua cidade. Particularmente depois de sua estada em Viena, deixou-se conduzir, nas críticas, pelas idéias avançadas de Berg, de Schoenberg e dos defensores da música dodecafônica moderna. Dá-se nesse período a gênese de conceitos fundamentais de seu pensamento estético: material musical, a consistência da obra singular; a construção e a expressão da obra de arte; a construção como solução de problemas colocados concretamente nas obras. Estas constelações, para Adorno, têm lugar "na experiência concreta do 'conhecimento histórico' que as obras musicais expõem àqueles que aprendem a 'pensar com os ouvidos" (Almeida, 2000, p. 190-203).

Em 1928, Adorno tenta, sem sucesso, a $\mathrm{H}$ abilitation à docência na Universidade de Frankfurt. A tese apresentada, 0 conceito de inconsciente na teoria transcendental da mente, não foi aprovada por Cornelius, assessorado por H orkheimer. Três anos atrás, Cornelius e seu assessor não tinham aceito a tese de Benjamin, A origem do drama barroco alemão (Benjamin, 1984). Adorno ficou muito irritado sobretudo contra $\mathrm{H}$ orkheimer, que, suspeitava, não haveria defendido suficientemente sua tese por não a considerar suficientemente marxista (cf. W iggershaus, 2002, p. 114). N uma segunda tentativa, em 1931, com o tema Ki erkegaard: a construção da estética, atinge seu objetivo. Seu novo orientador é o filósofo e teólogo Paul Tillich. Horkheimer também fez parte de sua banca. A tese, posteriormente transformada em livro (Adorno, 1969) e 
dedicada a Kracauer, defende a idéia de que a consciência estética, pela sua aparência de reconciliação, é capaz de fornecer um conhecimento mais acurado das contradições irreconciliáveis do mundo real. Adorno, servindo-se de uma "crítica aniquiladora e salvadora", desenvolveu no texto um materialismo de inspiração teológica, adquirido nos contatos com K racauer e Benjamin.

0 discurso inaugural como assistente de filosofia na U niversität J. W. G oethe intitulou-se "A atualidade da filosofia" e foi proferido no dia 8 de maio de 1931. Por meio dele, apresenta um programa para a interven ção filosófica contemporânea. Tinha, então, 28 anos. M esmo defendendo uma temática essencialmente filosófica, em uma tertúlia de pensadores acadêmicos, compõe-na em forma de ensaio e utiliza-se da ars inveniendi - a fantasia exata - como organon primordial da interpretação filosófica (Adorno, 1996). 0 discurso inaugural de Adorno aparentava ser um passo em direção a H orkheimer, mas, no fundo, permanecia um programa teológico-materialista no espírito de Benjamin e de Kracauer. $\mathrm{N}$ ão agradou nem a Horkheimer, nem a $\mathrm{M}$ annheim, nem ao próprio Kracauer. M as Adorno permaneceu fiel a seu programa, que significava, antes de tudo, apresentar os conceitos de Benjamin ao mundo científico universitário (W iggershaus, 2002, p. 125-126).

A partir de 1927, Benjamin passa a ser mais significativo para Adorno que K racauer. Viam-se durante as estadas de Benjamin em Frankfurt e de Adorno em Berlim. Aquele, oito anos mais velho que este, também era filho de um rico comerciante judeu, da capital alemã. Tinha publicado nos anos 20 dois trabal hos filosóficos sobre crítica de arte: As afinidades eletivas de $\mathrm{G}$ oethe e A origem do drama barroco alemão. De 1928 a 1932, reuniam-se com freqüência, em Frankfurt e redondeza, onde aconteceram, segundo informação do frankfurtiano, "conversações inolvidáveis". Benjamin leu para Adorno os "primeiros esboços" do Trabalho das passagens, trechos de A infância em Berlim em 1900; correspondiam-se amiúde. 0 s dois amigos, filósofos e estetas, desenvolveram "um tipo de trabalho em conjunto", alimentaram "preocupações comuns" (G agnebin, 2000). Adorno, em suas correspondências, faz referência a um "programa filosófico comum" (N obre, 1998, p. 60); familiarizou-se também com temas e categorias elaborados por seu amigo. Segundo BuckM orss, a partir de 1928, quase todos os seus escritos trazem a marca da linguagem de Benjamin (1981, p. 66). Posteriormente, algumas tensões entre os dois se fariam públicas. 
A primeira participação de Adorno na Revista do Instituto de Pesquisa Social, agora sob a direção de H orkheimer, dá-se em 1932 com um tema musical, "A situação social da música", em que traça as linhas básicas de uma estética materialista da música como modelo para a prática filosófica. D epois surgirão outros artigos analíticos, sobre música ou temáticas estéticas, publicados pela Revista do Instituto: Sobre o jazz (1936), Caráter fetichista da música e regressão da audição (1938), F ragmentos sobre Wagner (1939), Spengler hoje (1941), A investida de Veblen à cultura (1941). N uma avaliação quantitativa de suas produções, Adorno é muito mais músico que filósofo. Porém, como Thomas M ann observaria mais tarde (2001, p. 40), ele rejeitava a opção entre esteta e teórico e o conjunto de suas obras confirma essa observação. N o entanto, são raros os músicosfilósofos ou os filósofos-músicos! Precisam eles desenvolver um tipo de inteligência e de fantasia bem particular. $\mathrm{N}$ a sutil consideração de Türcke, "Adorno, enquanto insider tanto da música como da filosofia contemporâneas, também fez o papel do outsider em ambas as disciplinas" (Türcke, 2000, p. 5).

Ensinou filosofia em Frankfurt até 1933, quando teve sua venia legendi cassada pelos nazistas no dia de seu aniversário de 30 anos. A situação tensa em que a Alemanha se mergulhou a partir da gestão fascista obrigou Adorno a deixá-la, em 1934; seguiu para um exílio "temporário" na Inglaterra, na esperança de que o nazismo constituísse um fenômeno passageiro. Além do mais, arriscou-se em diversas viagens a Berlim para visitar sua noiva, Gretel Karplus, com quem se casou em 1937. H orkheimer, por sua vez, foi um dos primeiros intelectuais judeus a deixar a Alemanha; levou o Instituto de Pesquisa Social inicialmente para Genebra e, em 1934, para $\mathrm{N}$ ova York, vinculando-o à U niversidade de Colúmbia. Adorno ficou reduzido à condição de um "estudante honorário", no M erton College, em Oxford, e aproveitou seu tempo de desterro para retomar os estudos sobre $\mathrm{H}$ usserl e produzir o primeiro manuscrito de um livro que seria publicado em 1956, sobre a M etacrítica da epistemologia (cf. Jay, 1988, p. 31-32).

Em fevereiro de 1938 aceita o convite de $\mathrm{H}$ orkheimer e muda-se de Londres para N ova York e inicia seu trabalho no The Princeton Radio Research Project. D esempenhava então metade de suas funções no Instituto de Pesquisa Social e metade no M usic Study, com um grupo de pesquisadores, sob a direção de Paul Lazarsfeld, com financiamento da Rockefeller Foundation, para 
investigar a radiodifusão nos Estados Unidos. 0 projeto tinha como objetivo elevar o nível cultural dos programas e das audiências. "Procurei resolver o problema da dupla atividade mediante certa combinação de minhas tarefas científicas em ambos os campos. N os textos teóricos que escrevia então para o Instituto formulava os pontos de vista e as experiências que queria aproveitar no 'Radio Project'" (Adorno, 1995, p. 141).

Durante a vigência do projeto, de 1938 a 1941, Adorno produziu pelo menos sete textos críticos sobre a música no rádio: M usic in radio - memorando de 1938, de como a nova tecnologia afetava a qualidade musical; Pluging study - 1941, sobre a indústria do rádio na produção das canções de sucesso da música popular nos EUA; The radio synphony: an experiment in theory - 1941; O n popular music - publicado na Revista do Instituto, 1941; Analytical study of the NBC M usic Appreciation Hour - estudo da música clássica no rádio realizado entre 1938-1940; Current of music: elements for a radio theory - livro incompleto de Adorno, 1938 a 1941; A social critique of radio music - texto apresentado em encontro de especialistas da comunicação, com a presença de proprietários de emissoras e representantes da Rockefeller Foundation, que julgou o esforço de levar a teoria crítica para o terreno da comunicação um fracasso. A Fundação não renovou 0 contrato do Project por mais um biênio, como os organizadores do M usic Study esperavam (Carone, 2001, p. 2-10).

O s estudos de Adorno versaram sobre a música clássica, semiclássica (entretenimento elevado) e música popular, do ponto de vista de uma teoria social e crítica da música no rádio. E, na opinião de Carone, valem pelo que são: os melhores exemplos ou modelos de crítica da indústria cultural relativos ao período do apogeu do rádio e da hegemonia da música popular norte-americana no mundo (Carone, 2002, p. 5).

Em 1940, o Instituto de Pesquisa Social é transferido para LoS Angeles e, em 1941, Adorno, após terminar seu trabalho no Radio Project, parte para lá com a esposa Greta. N os próximos três anos, ele e H orkheimer se dedicam quase que exclusivamente à elaboração de um dos mais significativos livros do século XX, a Dialética do esclarecimento. Produto eminentemente filosófico, construído por dois pensadores alemães banidos em território norte-americano ponto mais desenvolvido do capitalismo monopolista -, que examina o infausto percurso da Ratio iluminista, que prometia tirar o homem da tutela do trono e do altar e dar a ele condições de 
"falar com sua própria boca", e, no entanto, enfeitiçada pelo vertiginoso "progresso" da dimensão instrumental dessa mesma Ratio, conduziu o homem a uma nova tutelagem: ser escravo das tecnologias que ele mesmo criou. A participação coletiva na composição de uma obra de longo fôlego teórico uniu ainda mais esses dois pensadores de índoles e estilos diferentes. E, apesar da terminologia cáustica e analítica dos ensaios, U lisses, as sereias e Juliette "jogam o charme" da poesia, da astúcia e da esperança em suas páginas sombrias (Adorno \& H orkheimer, 1986).

De julho de 1943 até janeiro de 1947, Adorno colaborou com Thomas M ann na composição do D outor Fausto - que traçava a biografia de um músico - , e a parceria entre os dois escritores - 0 literato e o filósofo - é um desses acontecimentos que engrandecem a literatura e a filosofia universais. Adorno contribuiu particularmente nos capítulos referentes às questões da arte e da música. M as esteve presente também em outros detalhes. Assim comenta $M$ ann com relação ao capítulo final do livro: "Sou tentado a dizer que sua maior contribuição ao capítulo não foi no âmbito da música, mas no da linguagem e suas nuanças, na forma com que, ao final, envolvem elementos teológicos, religiosos, morais" (M ann, 2001, p. 172). A leitura do texto em construção por Adorno, suas observações, as reformulações pacientes de $M$ ann, o progressivo embelezamento do texto... que experiência formativa marcante na vida de um filósofo/ compositor de 40 anos, em companhia eletiva de um amadurecido escritor literário de 68 anos! $M$ ann, qual humilde aprendiz, deixa-nos ver, ainda em referência ao último capítulo do livro, que, com base nas observações de Adorno, refez o texto e, algumas semanas depois, visita 0 amigo e lê para ele a parte modificada e pergunta-lhe se agora estava bom: "Em vez de responder, chamou a esposa, dizendo que ela precisava ouvir aquilo. Voltei a ler as duas folhas, olhei para eles - e não precisei perguntar mais nada" ( $M$ ann, 2001, p. 173).

Além de outros escritos publicados no período californiano, como Filosofia da nova música, 1945, Composing for the films (com $\mathrm{H}$ anns Eisler), 1947, Adorno compôs, de 1944 a 1947, um livro de crônicas filosófico-estéticas, a que deu o título de Minima moralia: reflexões a partir da vida danificada. $\mathrm{Na}$ observação de Jay, é esta a mais nietzschiana de todas as suas obras (1988, p. 41). $\mathrm{Na}$ opinião de outros comentadores, a mais elaborada realização estilística de Adorno. Composta por aforismos éticos, densos e instigantes, em que a ênfase micrológica de Kracauer e Benjamin 
tem papel de destaque, M inima moralia aborda, de forma irônica e literalmente bela, desde as ambigüidades dos refugiados em terras estrangeiras ("Todo intelectual emigrado é, sem exceção, um mutilado, e é bom que o admita para si mesmo se desejar evitar que isso Ihe seja cruelmente comunicado por trás das portas fortemente fechadas da auto-estima") até as conseqüências trágicas, para 0 indivíduo, de um mundo cada vez mais administrado, sob a capa de uma democracia de massas ("N ão há uma fenda no penhasco da ordem estabelecida à qual o praticante da ironia possa se apegar"). Apesar do pessimismo aparentemente compacto de seus textos filosóficos de exílio, Adorno jamais abandonou por completo a esperança de que a mudança radical ainda fosse possível. Pinceladas vivas estampam essa virtude em inúmeras aquarelas do texto ("N ão há mais beleza nem consolo algum fora do olhar que se volta para 0 horrível, a ele resiste e diante dele sustenta, com implacável consciência de negatividade, a possibilidade de algo melhor" Adorno, 1992a, p. 26; 185; 19).

De 1946 a 1949, Adorno integrou-se a um grupo de psicólogos sociais e psicólogos clínicos com formação psicanalítica da Universidade de Berkeley, Califórnia, para estudar a psicologia profunda, a dinâmica inconsciente de indivíduos propensos a discriminar grupos étnicos, políticos e religiosos. 0 livro, resultante da exaustiva e coletiva pesquisa, denominou-se A personalidade autoritária: estudos sobre preconceitos, publicado em N ova York, em 1950, e tornou-se verdadeiro modelo de psicologia empírica (Adorno et al., 1950).

Retorna à Alemanha em 1950 e é nomeado, junto com Horkheimer, professor catedrático do D epartamento de Filosofia da Universidade Johann Wolfgang Goethe. $\mathrm{O}$ s dois pensadores consagram, nos primeiros anos do retorno, o tempo todo, à docência e à reorganização do Instituto de Pesquisa Social em Frankfurt. N as décadas de 1950 e 1960, Adorno publica inúmeros escritos sobre filosofia e estética, entre as quais destaco: Prismas: crítica cultural e sociedade, 1955 (Adorno, 1998); D issonâncias: música do mundo administrado, 1956; M ahler: a fisionomia musical, 1960; Introdução à sociologia da música, 1962; Intervenções: novos modelos críticos, 1963; 0 jargão da autenticidade, 1964; Palavras e sinais: modelos críticos 2, 1969 (Adorno, 1995). Enfatizo, na nova fase alemã, três obras suas que revelam sobremaneira a presença formativa da filosofia e da estética na produção científica: 
$\mathrm{N}$ otas de Literatura, publicada em quatro volumes - de 1958 a 1974 - foi considerada pelo crítico da cultura Jameson a obra-prima de Adorno. O s quatro volumes abrangem o total de 30 ensaios e, em quase todos eles, é visível a presença de Benjamin. 0 termo "notas" indicia a relação da literatura com a música, como composição e, especialmente, no sentido de tentar exprimir o inexprimível; também sugere anotações, referência ao caráter fragmentário e experimental dos textos. Adorno inicia o primeiro volume de $\mathrm{N}$ otas com o texto 0 ensaio como forma, uma espécie de manifesto teórico-metodológico no qual sintetiza vários postulados sobre o impulso assistemático de seus escritos. Fica evidente no texto o rigoroso trabalho de construção e de expressão, bem como a intensa relação entre a filosofia e a estética. "A consciência da não-identidade entre 0 modo de expor e 0 objeto impõe ao ensaio um ilimitado esforço à exposição" (Adorno, apud Cohn, 1986, p. 181). 0 ensaio tornou-se a forma preferencial de Adorno construir sua filosofia.

Em 1966, surge um de seus principais escritos, Dialética negativa. 0 livro apresenta uma imanente ambigüidade, não apenas em seu título, mas também na forma como foi construído. "U ma de suas intenções básicas é justamente extrair desenvolvimentos de seu título paradoxal", diz o autor (Adorno, 1975, p. 7). Conserva ele formalmente as características dos trabalhos logicamente estruturados; porém, na verdade, seus capítulos são formados por uma infinidade de pequenos fragmentos. A pesar de o texto se apresentar como essencialmente reflexivo, a dialética adorniana busca, por meio do pensar negativo, "incorporar os impulsos corporais esquecidos nas figuras mais elevadas da abstração conceitual", acolhendo "as moções pulsionais que constituem a razão de ser de todo pensamento" (C hiarello, 2002, p. 7). Há uma preocupação de fundo do autor em resgatar os elementos retóricos e sensuais da linguagem, bem como sua capacidade expressiva. Türcke identifica no transcurso da Dialética negativa um programado procedimento musical: a composição apresenta-se em forma de um tema com inúmeras variações, que, por seus ritornelos e contrapontos, revelam cada vez mais o tema; cada variação aponta para as outras, fazendo com que o conjunto de todas forme uma estrutura de explicação mútua (T ürcke, 2000, p. 7). N a Dialética negativa a filosofia crítica faz-se música dissonante.

Em 1970 foi publicada, em edição póstuma e inacabada, Teoria estética. Adorno tinha falecido subitamente a 6 de agosto de 
1969, em Visp, Suíça, onde passava suas férias. Talvez os difíceis conflitos com os estudantes nos anos 68/69, quando então dirigia 0 Instituto de Pesquisa Social, tenham precipitado o seu fim. A organização da obra para publicação foi feita por sua esposa G reta e por Rolf Tiedemann. 0 livro apresenta-se desdobrado em 175 aforismos. Adorno defende o poder crítico da arte modernista e evidencia o momento negativo intrínseco que a obra de arte exerce em sua relação tensa com a sociedade. Sua existência já é um protesto veemente contra o sistema opressivo que a ordem impõe. A experiência de Adorno como compositor e pianista, seus ensaios sobre música e literatura, seus conhecimentos filosóficos e sociológicos fazem da Teoria estética a síntese amadurecida de suas reflexões teóricas. Fundamenta-se em clássicos da arte e da filosofia. Seus autores mais citados são, entre os compositores: Bach, M ozart, Beethoven, Wagner e Schoenberg; entre os literatos: Goethe, Baudelaire, Valery, Brecht e Beckett; entre os teóricos: Kant, H egel, $\mathrm{N}$ ietzsche e Benjamin. $\mathrm{H}$ á uma relação de dependência recíproca entre arte e filosofia na Teoria estética, à semelhança do que já existia na Dialética negativa. "A arte necessita da filosofia, que a interpreta, para dizer o que ela não consegue dizer, conquanto só através da arte pode ser dito ao não ser dito" (Adorno, 1992b, p. 89; cf. Pucci et al., 2003, p. 94-108).

0 percurso realizado até aqui nos mostra que a relação entre música e filosofia na vida e nos escritos de Adorno não se realiza como mera aproximação externa, nem por meio de "pseudomorfoses". D e um lado, o toque artístico dado pela música não invade o pensamento como algo alienígena; antes imprime ressonância a sua própria vivacidade. Possibilitar, por intermédio das notas, espaço às associações e aos saltos de um pensamento concreto é mantêlo vivo, em conexão direta com o objeto, sempre aspirando a mais. São as coisas que, inquietas por suas necessidades íntimas, estimulam o gingado e a libido do pensar. E não o objeto submisso que se encaixa, ordenadamente, em gavetas conceituais adrede elaboradas. D e outro lado, são proibidas as "pseudomorfoses" sob pena de destruição recíproca! A filosofia tem que continuar filosofia, mesmo sendo partilhada pela música; e a música continuar música, mesmo tendo suas notas penetradas por áridos conceitos. $\mathrm{N}$ ão há uma relação de dependência entre elas e sim de aperfeiçoamento, exposição e densidade. Os escritos filosóficos de Adorno são testemunhas do bem que a música Ihes faz. 
Foi pacientemente gestado por Adorno um estilo retóricoensaístico que dá à filosofia uma dimensão sui generis. Há um esforço incomensurável de o pensamento dizer o indizível, apontando insistentemente para além de si mesmo. É a "expressão do inexprimível" que irmana música e filosofia (D uarte, 1997, p. 85-109). Escrever ensaisticamente é perseguir as exigências internas da obra no querer se expressar totalmente a si mesma, mesmo tendo ciência de nunca conseguir realizar essa sua intenção ousada.

A integração do elemento expressivo ao discurso racional da filosofia interliga-se, em Adorno, a uma renovação da própria concepção de dialética: "D ialética, cujo sentido literal é organon do pensamento, seria a tentativa de salvar de maneira crítica o momento retórico: aproximar a coisa e a expressão entre si até indiferenciá-las" (Adorno, 1975, p. 66). M inima moralia e os escritos amadurecidos de Adorno, $\mathrm{N}$ otas de literatura, D ialética negativa e Teoria estética, foram elaborados como epifania dessa concepção: "C onsiderar a filosofia com os olhos do artista e a arte, sobretudo a música, com os olhos do filósofo" (T ürcke, 2000, p. 5).

A filosofia em Adorno é conduzida tensamente pelos próprios impulsos do pensamento em sua sedução incontrolável de possuir o objeto. E os pensamentos in fieri criam sua própria dinâmica, seu ambiente, que estimulam curiosidades, associações, "vagabundagens por mundos inteligíveis", no duro esforço por expressar aquilo que ainda não se fez luz.

Recebido e aprovado em maio de 2003.

\section{Referências bibliográficas}

ADORNO, T.W. Kierkegaard: ensayo. Versión de Roberto J. Vernengo. Caracas: M onte Avila, 1969.

AD ORN O, T.W. Dialectica negativa. Madri: Taurus, 1975.

AD ORN O, T.W. 0 ensaio como forma. In: $\mathrm{COHN}, \mathrm{G}$. Theodor Adorno: sociologia. São Paulo: Ática, 1986.

AD O RN 0, T.W. M inima moralia: reflexões a partir da vida danificada. São Paulo: Ática, 1992a.

AD O RN O, T.W. Teoria estética. Lisboa: Edições 70, 1992b. 
AD O RN O, T.W. Experiências científicas nos Estados Unidos. In: Adorno, T.W. Palavras e sinais. modelos críticos 2. Petrópolis: Vozes, 1995.

ADORNO, T.W. Die aktualität der philosophie. In: Adorno, T.W. Philosophische frühschriften. Vol. 1. Frankfurt am M ain: Suhrkamp, 1996.

AD O RN O, T.W. Prismas: crítica cultural e sociedade. São Paulo: Ática, 1998.

AD O RN O, T.W. Carta a Thomas M ann de 5 de julho de 1948. FoIha de S. Paulo, São Paulo, 10 nov. 2002. Caderno M ais!

ADORN O, T.W. et al. The authoritarian personality. Nova York: H arper, 1950.

AD ORN O, T.W.; HORKHEIMER, M. Dialética do esclarecimento: fragmentos filosóficos. 2aㅡ ed. Rio de Janeiro: Zahar, 1986.

ALM EID A, J.M .B. M úsica e verdade: a estética crítica de Theodor Adorno. 2000. 175f. Tese (D outorado em Filosofia) - Faculdade de Filosofia, Letras e Ciências H umanas, U niversidade de São Paulo, São Paulo.

BEN JAM IN, W. A origem do drama barroco alemão. São Paulo: Brasiliense, 1984.

BU CK-M O RSS, S. O rigen de la dialéctica negativa: Theodor W. Adorno, Walter Benjamin y el Instituto de Frankfurt. M éxico: Siglo Ventiuno, 1981.

CARON E, I. Teoria crítica e pesquisa empírica na psicologia: relatório de estágio de pós-doutoramento na Universidade de Colúmbia. São Paulo: FAPESP, 2001. (mimeo)

CARO NE, I. Adorno e a música no ar. Conferência realizada no Colóquio Nacional "Tecnologia, cultura e formação... ainda Auschwitz", na un IM EP, Piracicaba, em 17 de maio de 2002.

CHIARELLO, M.G. A filosofia, a arte e o inominável: três estudos sobre a dor da finitude na obra de T. W. Adorno. 2002. 241f. Tese (D outorado) - Instituto de Filosofia e Ciências Humanas, Universidade Estadual de Campinas, Campinas. 
DUARTE, R. Da filosofia da música à música da filosofia. In: D UARTE, R. Adornos: nove ensaios sobre o filósofo frankfurtiano. Belo H orizonte: UFM G, 1997.

GAGN EBIN , J.M. Divergências e convergências metodológicas sobre 0 método dialético entre Adorno e Benjamin. Piracicaba: un Im EP, 2000.

JAY, M. As idéas de Adorno. São Paulo: Cultrix, 1988.

MAN N, T. Doutor Fausto: a vida do compositor alemão Adrian Leverkühn narrada por um amigo. Rio de Janeiro: N ova Fronteira, 2000.

M AN N , T. A gênese do doutor Fausto. Lisboa: M andarim, 2001.

NO BRE, M. A dialética negativa de Theodor W. Adorno: a ontologia do estado falso. São Paulo: Iluminuras, 1998.

PUCCI, B.; OLIVEIRA, N.R.; ZUIN, A.A.S. Adorno: o poder educativo do pensamento crítico. 3a ed. Petrópolis: Vozes, 2003.

TÜ RCKE, C. Pronto-socorro para Adorno: fragmentos introdutórios à dialética negativa. São Carlos: UfsCAR, 2000.

WIGGERSH AUS, R. A Escola de Frankfurt: história, desenvolvimento teórico, significação política. Rio de Janeiro: Difel, 2002. 